\title{
KAJIAN KOHESI GRAMATIKAL SUBTITUSI DAN ELIPSIS DALAM NOVEL KHOTBAH DI ATAS BUKIT KARYA KUNTOWIJOYO
}

\author{
Asep Muhyidin \\ FKIP Universitas Sultan Ageng Tirtayasa \\ muhyidin21@untirta.ac.id
}

\begin{abstract}
Abstrak
Penelitian ini bertujuan mendeskripsikan penggunaan piranti kohesi gramatikal subtitusi dan elipsis dalam novel Khotbah di Atas Bukit karya Kuntowijoyo. Data yang diambil yaitu satuan lingual berupa kalimat-kalimat yang memiliki piranti kohesi gramatikal subtitusi dan elipsis. Sumber data dalam penelitian ini berupa sumber data tertulis berupa paragraf-paragraf yang terdapat pada novel. Metode yang digunakan untuk mengumpulkan data pada penelitian ini adalah simak. Analisis data dalam penelitian ini menggunakan metode agih. Hasil penelitian ditemukan piranti subtitusi berupa subtitusi nominal sebanyak 12 buah, subtitusi verbal 6 buah, dan subtitusi klausal 8 buah. Kemudian, piranti elipsis berupa elipsis nominal sebanyak 23 buah, elipsis verbal tidak ditemukan, dan elipsis klausal sebanyak 1 buah. Hasil penelitian dapat diimplikasikan dalam pembelajaran bahasa Indonesia di SMA. Hal ini karena di dalam kurikulum 2013 terdapat komponen pembelajaran yang berkaitan dengan penggunaan kohesi gramatikal subtitusi dan elipsis dalam wacana novel.
\end{abstract}

Kata Kunci: Subtitusi dan Elipsis, Novel, Pembelajaran Bahasa Indonesia

\begin{abstract}
This study aims to describe the use of grammatical cohesion substitution and ellipsis in Khotbah di Atas Bukit novel by Kuntowijoyo. The data were lingual unit in the form of sentences with substitution and ellipsis markers. The data were sources were paragraphs in the novel. The data were collected through reading. They were analyzed by the distributive method. The finding shows that where are 12 nominal substitution, 6 verbal substitution, and 8 substitution clauses. Then, there are 23 nominal ellipsis, verbal ellipsis was not found, and 1 clausal ellipsis. The findings can be utilized in the Indonesian language learning at senior high schools. This is because in the curriculum 2013 there is a learning component related to the use of substitution and ellipsis grammatical cohesion in novel discourse.
\end{abstract}

Keywords: Substitution and Ellipsis, Novel, Indonesian Language Instruction

\section{PENDAHULUAN}

Salah satu fungsi bahasa Indonesia adalah sebagai alat komunikasi. Sebagai alat komunikasi, bahasa Indonesia tidak dirinci dalam bentuk bunyi, frasa, klausa ataupun kalimat secara terpisah-pisah, melainkan bahasa dipakai dalam wujud klausa maupun kalimat yang saling berkaitan. Dalam kalimat majemuk, klausa pertama berkaitan dengan klausa berikutnya. Dalam paragraf, kalimat pertama menyebabkan timbulnya 
kalimat kedua, kalimat kedua menjadi acuan kalimat ketiga, kalimat ketiga mengacu kembali ke kalimat pertama dan seterusnya. Rentetan kalimat yang berkaitan yang menghubungkan proposisi yang satu dengan proposisi yang lain itu membentuk kesatuan yang dinamakan wacana (Alwi dkk., 2014).

Wacana adalah rangkaian kalimat yang serasi, yang menghubungkan proposisi satu dengan proposisi lain, kalimat satu dengan kalimat lain, membentuk satu kesatuan. Pengertian satu kalimat dihubungkan dengan kalimat lain dan tidak ditafsirkan satu persatu kalimat saja. Kesatuan bahasa itu bisa panjang bisa pendek. Sebagai sebuah teks, wacana bukan urutan kalimat yang tidak mempunyai ikatan sesamanya, bukan kalimat-kalimat yang dideretkan begitu saja (Eriyanto, 2001). Wacana yang baik adalah wacana yang harus memperhatikan hubungan antarkalimat. Hal ini harus selalu diperhatikan untuk memelihara keterkaitan dan keruntutan antarkalimat. Sejalan dengan pandangan bahwa bahasa itu terdiri atas bentuk dan makna. Kohesi dan koherensi merupakan unsur hakikat wacana, unsur yang turut menentukan keutuhan wacana. Dalam kata kohesi tersirat pengertian kepaduan, keutuhan, dan kata koherensi terkandung pengertian pertalian dan hubungan. Apabila dikaitkan dengan aspek bentuk dan makna maka dapatlah kita katakan bahwa kohesi mengacu pada aspek bentuk dan koherensi.

Novel merupakan salah satu jenis wacana fiksi. Wacana fiksi adalah wacana yang menyajikan objek dan menimbulkan daya khayal atau pengalaman melalui kesankesan imajinatif, bukan kenyataan (Sudaryat, 2009). Novel termasuk ke dalam wacana fiksi yang berupa wacana prosa. Novel merupakan salah satu jenis karya sastra modern yang berbentuk prosa fiksi. Novel biasanya berisi tentang potret kehidupan manusia baik berupa percintaan, persahabatan, keagamaan, dan lain sebagainya. Selain itu, novel juga merupakan media untuk menyampaikan nilai-nilai kehidupan seperti nilai moral, sosial, budaya, dan lain-lain. Oleh karena itu, novel dapat dijadikan sebagai salah satu sumber belajar untuk membelajarkan nilai-nilai dalam kehidupan pada anak maupun remaja.

Dalam sebuah wacana novel hubungan antarkalimat harus selalu diperhatikan untuk memelihara keterkaitan dan keruntutan antarkalimat. Keterkaitan yang padu antarkalimat dalam sebuah wacana novel merupakan syarat penting dalam pembentukan sebuah wacana karena dengan keterkaitan yang padu, wacana akan menjadi utuh. Keterkaitan antarkalimat pengembang topik secara semantis disebut koherensi sedangkan keterkaitan secara leksikal dan gramatikal disebut kohesi (Klimova dan Hubackopa, 2014). Sarana kohesi dan sarana koherensi dapat digunakan sebagai penghubung antarkalimat dan antarparagraf. Keberadaan wacana dalam novel sangat penting karena wacana membantu memberikan penafsiran tentang makna ujaran dalam teks. Di samping itu, novel yang merupakan komunikasi pengarang kepada pembacanya harus mudah dipahami dan dapat dicerna dengan baik. Bahasa yang digunakan dalam novel harus bervariatif, oleh karena itu pengarang dapat menggunakan penanda kohesi gramatikal subtitusi dan ellipsis.

Subtitusi adalah penyulihan suatu unsur wacana dengan unsur lain yang acuannya tetap sama, dalam hubungan antarbentuk kata atau bentuk lain yang lebih besar daripada kata, seperti frase atau klausa (Halliday dan Hassan, 1976). Kemudian, menurut Cook (1989), subtitusi adalah salah satu piranti kohesi berupa kata tertentu menggantikan kata yang lain, biasanya dapat berupa kata, frasa, klausa atau satuan lingual lain. Biasanya subtitusi digunakan untuk menggantikan pengulangan unsur bahasa. Subtitusi adalah proses atau hasil penggantian unsur bahasa oleh unsur lain 
dalam satuan yang lebih besar untuk memperoleh unsur-unsur pembeda atau untuk menjelaskan suatu struktur tertentu (Kridalaksana, 2008). Ada tiga tipe subtitusi, yaitu subtitusi nominal, verbal, dan klausal (Nunan, 1992).

Elipsis adalah proses yang tidak melibatkan perpindahan melainkan penghilangan suatu unsur sintaksis yang bisa diidentifikasi dari pernyataan sebelumnya (Lobeck, 1995; Mahalli, Valipour \& Mahdavi, 2016)). Elipsis merupakan fenomena yang berkaitan dengan sintaksis secara teoritis, dimana struktur tertentu yang dihadirkan mempunyai tingkat representasi yang dalam, tetapi tidak diucapkan. Dapat disimpulkan bahwa elipsis adalah suatu penghilangan frasa ataupun klausa didalam sebuah kalimat yang tidak mempengaruhi arti dari kalimat itu sendiri. Tujuan dari elipsis sendiri adalah untuk mencegah pengulangan kata-kata yang tidak perlu dalam sebuah kalimat. Elipsis terjadi jika sebagian unsur struktural yang penting dilesapkan dan kalimat atau suatu klausa yang hanya dapat ditemukan kembali dengan mengacu pada suatu unsur di dalam teks yang mendahuluinya (Nunan, 1992). Elipsis yaitu penghilangan satu bagian dari unsur kalimat itu (Lubis, 1994). Sama dengan subtitusi, elipsis pun terbagi menjadi tiga tipe, yaitu elipsis nominal, verbal, dan klausal. Terjadinya elipsis sama dengan subtitusi tetapi yang membedakannya adalah elipsis ini disubtitusi oleh sesuatu yang kosong atau sesuatu yang tidak ada. Dalam teks naratif banyak ditemukan elipsis untuk keefektifan kalimat (Rosyidah, 2015)

Penelitian ini memilih novel Khotbah di Atas Bukit karya Kuntowijoyo karena novel ini berupa novel yang bersifat naratif. Wacana naratif adalah rangkaian tuturan yang menceritakan atau menyajikan suatu kejadian melalui penonjolan tokoh atau pelaku dengan maksud memperluas pengetahuan pembaca atau pendengar (Syamsuddin, 1998). Kekuatan wacana ini terletak pada urutan cerita berdasarkan waktu dan cara-cara bercerita yang diatur melalui plot. Novel ini mengetengahkan pergulatan dalam batin manusia di antara kekuatan spiritual dan kekuatan benda-benda material. Tokoh utama Barman, seorang laki-laki tua pensiunan PNS berusia 65 tahun hidup menyepi di sebuah bukit. Barman ditemani perempuan cantik bernama Popi yang siap melayani apa yang dibutuhkannya. Barman menemukan hakikat hidup di bukit itu. Novel ini terdiri atas 173 halaman dan diterbitkan oleh Bentang di Yogyakarta pada tahun 1993.

Dalam struktur wacana novel, aspek kohesi dan koherensi sangat diperlukan keberadaannya untuk menata pertalian antara proposisi yang satu dengan yang lainnya untuk mendapatkan keutuhan. Untuk memperoleh wacana yang baik dan utuh, kalimatkalimat pendukung wacana harus kohesif (Alwi dkk., 2014). Hanya dengan hubungan kohesif seperti inilah unsur-unsur di dalam wacana dapat diinterpretasi sesuai dengan kebergantungannya dengan unsur lain. Hubungan kohesif ini sering ditandai oleh kehadiran penanda khusus yang bersifat formal. Penanda formal ini dapat berupa aspek gramatikal maupun aspek leksikal. Salah satu penanda tersebut adalan subtitusi dan elipsis.

Penelitian mengenai kohesi gramatikal subtitusi dan elipsis dalam wacana novel telah banyak dilakukan oleh peneliti lain. Diantaranya dilakukan oleh Jumhur, N.A. (2014), Widiani (2016), Wiyanti (2016), Aryanti \& Sari (2018), dan Azwan (2019).

Jumhur (2014) melakukan penelitian mengenai elipsis dalam wacana novel Slated karya Teri Terry. Berdasarkan hasil penelitian ditemukan tiga jenis elipsis, yaitu elipsis nominal, verbal, dan klausal. Widiani (2016) melakukan studi mengenai substitusi dan ellipsis yang ditemukan pada kalimat-kalimat di dalam sebuah novel yang berjudul Sweet Frannie. Substitusi dan elipsis memiliki jenis yang sama yang dibagi 
dalam tiga bagian yaitu nomina, verba dan klausa. Jenis-jenis tersebut dapat ditemukan dalam novel "Sweet Frannie" yang dianalisis sesuai dengan teori Halliday dan Hassan (1976) mengenai substitusi dan ellipsis. Hasil dari penelitian studi ini menunjukkan bahwa seluruh tipe substitusi berdasarkan teori dari Halliday and Hassan (1976) yakni substitusi nomina, substitusi verba, dan substitusi klausa ditemukan dalam novel "Sweet Frannie". Sama halnya dengan substitusi, seluruh tipe dari ellipsis yakni nomina ellipsis, verba ellipsis dan klausa ellipsis telah ditemukan dalam novel Sweet Frannie.

Wiyanti (2016) melakukan penelitian tentang kohesi gramatikal subtitusi dan elipsis dalam novel Laskar Pelangi karya Andrea Hirata. Metode penelitian yang digunakan adalah kualitatif dengan teknik analisis isi. Hasil penelitian menunjukkan pemakaian unsur bahasa berupa kata, frasa, klausa, dan kalimat sebagai perujuk dua kalimat berpasangan untuk mengetahui hubungan kohesif belum merata. Ditemukan subtitusi nominal, verbal, dan klausal. Lalu, elipsis nominal, verbal, dan klausal.

Penelitian dilakukan oleh Aryanti dan Sari (2018) berjudul "Verba Ellipsis in Charles Dickens's Novel: Bleak House" membahas tentang keberadaan elipsis verba dalam klausa pada sebuah novel. Penelitian ini menggunakan metode deskriptif untuk menganalisa data berdasarkan pembahasan. Data diambil dari novel Bleak House karya Charles Dickens karena banyak terdapat kata yang dihilangkan meskipun pembaca masih dapat mengerti. Berdasarkan analisa, data bisa diindikasi sebagai elipsis verba. Sebagai tambahan, penelitian ini dibuat untuk menjelaskan peran elipsis verba pada sebuah klausa atau pada sebuah percakapan di dalam novel. Selain itu, penelitian ini juga melengkapi penelitian sebelumnya untuk menjelaskan lebih dalam tentang elipsis khusunya pada elipsis verba.

Masniati dan Azwan (2019) melakukan penelitian tentang elipsis dalam novel The Short Second Life of Bree Tanner. Penelitian ini bertujuan untuk menjelaskan penggunaan jenis-jenis kalimat elipsis dalam novel. Penelitian ini menggunakan metode kualitatif. Analisis data menggunakan analisis sintaksis. Berdasarkan temuan penelitian, peneliti menyimpulkan ditemukan tiga jenis kalimat elipsis, yaitu elipsis nomina, elipsis verbal, dan elipsis klausal.

Berdasarkan latar belakang yang telah diuraikan di atas, fokus penelitian ini adalah penggunaan kohesi gramatikal dalam novel Khotbah di Atas Bukit karya Kuntowijoyo. Adapun subfokusnya adalah penggunaan subtitusi dan elipsis dalam novel Khotbah di Atas Bukit karya Kuntowijoyo. Berdasarkan latar belakang, fokus dan subfokus penelitian, maka rumusan masalahnya adalah bagaimana penggunaan subtitusi dan elispsis dalam novel Khotbah di Atas Bukit karya Kuntowijoyo serta implikasinya bagi pembelajaran bahasa Indonesia di SMA?

\section{METODE PENELITIAN}

Penelitian ini menggunakan metode dekriptif kualitatif. Penelitian ini berusaha menyelidiki penggunaan subtitusi dan elipsis yang digunakan dalam novel dalam novel Khotbah di Atas Bukit karya Kuntowijoyo. Indonesia di SMA. Sumber data dalam penelitian ini berupa sumber data tertulis yaitu paragraf-paragraf yang terdapat pada novel Khotbah di Atas Bukit karya Kuntowijoyo. Adapun data yang diambil yaitu satuan lingual berupa kalimat-kalimat yang memiliki penanda kohesi gramatikal berupa subtitusi dan elipsis yang terdapat dalam dalam novel Khotbah di Atas Bukit karya Kuntowijoyo.

Metode pengumpulan data dalam penelitian ini menggunakan metode simak dan catat (Sudaryanto, 2015). Metode simak yang digunakan dalam penelitian ini yaitu 
menyimak tulisan yang ada dalam novel Khotbah di Atas Bukit karya Kuntowijoyo. Metode catat digunakan untuk mencatat data dalam kartu data yang sudah disiapkan. Kartu data tersebut berisi dua bagian, yaitu bagian deskripsi dan bagain refleksi. Bagian deskripsi digunakan untuk mencatat penggalan wacana yang mengandung penanda kohesi gramatikal subtitusi dan elipsis. Sementara itu, bagian refleksi berisi hasil interpretasi terhadap penggalan wacana yang mengandung subtitusi dan elipsis tersebut.

Langkah-langkah dalam mengumpulkan data adalah: 1) membaca secara teliti wacana novel Khotbah di Atas Bukit karya Kuntowijoyo; 2) menyimak paragraf demi paragraf untuk menemukan ada tidaknya penanda kohesi gramatikal subtitusi dan elipsis; 3) menginventarisasi penggalan wacana berupa paragraf untuk menemukan ada tidaknya penanda kohesi gramatikal subtitusi dan elipsis dengan mencatatkannya pada kartu data; 4) mengelompokkan penggalan-penggalan wacana tersebut ke dalam klasifikasi penanda kohesi gramatikal subtitusi dan ellipsis, dan 5) menuliskan hasil klasifikasi tersebut pada kartu data.

Pemeriksaan keabsahan data dalam penelitian ini menggunakan teknik triangulasi. Denzin (dalam Moleong 2012:330) membagi teknik pemeriksaan keabsahan data dalam empat jenis yakni 1) triangulasi sumber; 2) triangulasi metode; 3) triangulasi penyidik; dan 4) triangulasi teori. Triangulasi yang digunakan dalam penelitian ini ialah triangulasi teori. Keabsahan data yang ditemukan berlandaskan pada teori yang ada. Dalam penelitian ini, triangulasi teori dilakukan dengan menentukan pola atau bentuk melalui analisis yang berdasarkan pada teori kohesi gramatikal subtitusi dan elipsis.

Analisis data dalam penelitian ini menggunakan metode agih (Sudaryanto, 2015: 31). Langkah-langkah penelitian dalam menganalisis data adalah: 1) membagi wacana menjadi penggalan-penggalan wacana; 2) membagi kalimat menjadi beberapa unsur dan mengambil satu unsur yang dianggap sebagai penanda kohesi gramatikal subtitusi dan elipsis untuk dianalisis lebih lanjut; 3) menggunakan teknik ganti yaitu dengan mengganti penanda kohesi gramatikal subtitusi dan elipsis dengan anteseden yang dapat diterima (gramatikal); 4) menggunakan teknik baca markah untuk melihat langsung letak anteseden (sebagai penanda) yang diacu oleh penanda kohesi gramatikal subtitusi dan elipsis dan 5) menarik inferensi serta simpulan tentang penggunaan penanda kohesi gramatikal subtitusi dan elipsis.

\section{HASIL DAN PEMBAHASAN}

\section{Hasil}

Tabel 1 Temuan Piranti Subtitusi

\begin{tabular}{llc}
\hline No. & \multicolumn{1}{c}{ Klasifikasi } & Jumlah \\
\hline 1. & Subtitusi Nominal & 12 \\
2. & Subtitusi Verbal & 6 \\
3. & Subtitusi Klausal & 8 \\
& Jumlah & 26 \\
\hline
\end{tabular}


Tabel 2 Temuan Piranti Elipsis

\begin{tabular}{llc}
\hline No. & \multicolumn{1}{c}{ Klasifikasi } & Jumlah \\
\hline 1. & Elipsis Nominal & 23 \\
2. & Elipsis Verbal & 0 \\
3. & Elipsis Klausal & 1 \\
& Jumlah & 24 \\
\hline
\end{tabular}

\section{Pembahasan}

\section{Kohesi Gramatikal Subtitusi}

Piranti kohesi gramatikal subtitusi yang ditemukan dalam penelitian ini berjumlah 26 buah. Subtitusi nominal ditemukan sebanyak 12 piranti, subtitusi verbal sebanyak 6 piranti, dan subtitusi klausal sebanyak 8 piranti. Subtitusi adalah penggantian suatu unsur dalam teks oleh unsur lain (Zaimar dan Harahap, 2011). Berikut ini adalah contoh data tersebut.

(1) Barman mengelakkan belaian Popi, menghindar dan menggumam mengulangi jawaban itu. Popi membiarkan laki-laki membuka pintu muka. (Kuntowijoyo, 1993: 65)

(2) Sore sebelumnya, diingatnya betul, Barman bercanda dengannya di dalam petamanan itu. Sekarang, lebih dari sebelumnya, ia melihat laki-laki tua yang sebenarnya. (Kuntowijoyo, 1993: 60)

(3) Mereka berkerumun sekitar Barman. Laki-laki tua kurus yang dikerumuninya itu segar bugar. (Kuntowijoyo, 1993: 119)

(4) Namun, suatu di malam-malam ia ingin sekali mengunjungi Popi, kekasih yang ditinggalkannya itu. (Kuntowijoyo, 1993: 124)

(5) Namun barangkali Popi ialah sejenis perempuan yang telah mengambil suatu keputusan. Bidadarinya yang cantik itu sekarang dicintainya. (Kuntowijoyo, 1993: 106)

Penggunaan subtitusi nominal dapat dilihat pada data (1 s.d. 5) yaitu satuan lingual berupa nomina digantikan oleh satuan lingual berupa nomina pula. Pada data (1) satuan lingual laki-laki menggantikan satuan Barman yang terdapat pada kalimat sebelumnya. Ini berarti kata mensubtitusi kata. Kemudian, pada data (2) satuan lingual laki-laki tua menggantikan satuan Barman yang terdapat pada kalimat sebelumnya. Di sini terjadi frasa mensubtitusi kata. Lalu, data (3) satuan lingual laki-laki tua kurus menggantikan satuan Barman yang terdapat pada kalimat sebelumnya. Menurut Alwi dkk. (2014), dalam frasa nominal, inti dapat diperluas ke kiri atau ke kanan. Perluasan ke kanan, suatu inti dapat dikuti oleh adjektiva. Hal ini seperti terjadi pada frasa lakilaki tua pada data (2) diperluas menjadi laki-laki tua kurus. Dalam konteks novel, tokoh Barman digambarkan sebagai laki-laki tua yang berperawakan tinggi kurus.

Data (4) satuan lingual berupa nomina kekasih menggantikan satuan lingual nomina Popi. Sedangkan pada data (5) satuan lingual bidadari menggantikan satuan lingual nomina Popi. Ini terjadi kata mensubtitusi kata dan termasuk kategori subtitusi nominal. Penggantian tokoh Popi dengan sebutan kekasih dan bidadari merupakan metafora yang menggambarkan tokoh Popi tersebut sebagai seorang yang cantik. Popi 
merupakan perempuan yang menemani tokoh Barman untuk tinggal di bukit. Salah satu gaya penulisan novel sebagai karya sastra adalah banyak mengandung metafora.

(6) Dokter itu bilang, "Sesehat kuda papimu ini, Bob." Ia gembira dengan ungkapan itu . (Kuntowijoyo, 1993: 15)

(7) Barman berkeras hendak membawa keranjang itu dengan tangannya, tetapi Popi menolak. Kita mesti cari orang lain, pap. Engkau terlalu tua untuk pekerjaan ini, demikian tangkapan Barman. (Kuntowijoyo, 1993: 58)

Pada data (6) pronomina penunjuk itu merupakan bentuk linguistik yang merupakan subtitusi dari satuan sesehat kuda yang terdapat pada kalimat sebelumnya. Munculnya pronomina penunjuk tersebut untuk menghindari pengulangan-pengulangan, sehingga penggunaan kalimat-kalimat dalam novel menjadi lebih bervariasi.

Pronomina penunjuk ini pada data (7) merupakan satuan lingual yang mensubtitusi satuan lingual membawa keranjang. Dalam konteks novel, Popi tidak tega jika Barman yang membawa keranjang belanjaan di pasar karena dia terlalu tua.

(8) Engkau sudah tua, Barman. Pikiran ini sempat pula menyelinap di sela kegairahannya. (Kuntowijoyo, 1993: 7)

(9) Ia ingin benar mengetuk pintu, dan kembali tidur di samping perempuan itu. Itu tentu saja tidak dilakukannya, seperti ia sudah membuat perjanjian dengan Popi. (Kuntowijoyo, 1993: 71)

Pada data (8), pronomina penunjuk ini mensubtitusi seluruhnya kalimat sebelumnya, yaitu Engkau sudah tua, Barman. Kemudian, pada data (9) pronomina penunjuk itu merupakan bentuk linguistik yang merupakan subtitusi dari kalimat yang telah ada sebelumnya, yaitu Ia ingin benar mengetuk pintu, dan kembali tidur di samping perempuan itu. Dari segi arahnya, relasi ini merupakan relasi anafora.

Subtitusi adalah hubungan antarunsur yang berada dalam teks, sesuatu yang digunakan untuk menggantikan pengulangan (Zaimar dan Harahap, 2011). Dalam membangun wacana yang baik selalu ada pengulangan. Suatu unsur seringkali diulangulang untuk memperjelas makna. Itulah sebabnya diperlukan unsur-unsur yang lain untuk menggantikan pengulangan kata, antara lain dengan unsur gramatikal agar tidak membosankan, dan wacana tampak lebih bervariasi. Menurut Sumarlam (2003) fungsi subtitusi antara lain untuk 1) menghadirkan variasi bentuk, 2) menciptakan dinamisasi narasi, 3) menghilangkan kenonotonan, dan 4) memperoleh unsur pembeda. Hal ini sepaham dengan penelitian yang dilakukan oleh Youlanda, Zahar, dan Sujoko (2018) bahwa proses penggantian satuan lingual dengan satuan lingual lain dilakukan pengarang di dalam karya sastra guna memperoleh unsur bahasa yang lebih besar serta menghilangkan kemonotonan yang diakibatkan pengulangan kata-kata atau kalimatkalimat yang sama.

Dalam konteks wacana novel, substitusi perlu digunakan untuk menghindari pengulangan unsur-unsur bahasa yang sama, sehingga penulisan paragraf dalam wacana novel tersebut tidak monoton. Cerita yang disusun menjadi tampak apik dan lebih variatif. Dengan adanya substitusi pada paragraf dalam wacana novel, penekanan terhadap tema utama dapat dilakukan tanpa menimbulkan kebosanan yang akan menganggu pemahaman pembaca. Selain menghilangkan kemonotonan dengan menghindari pengulangan pada unsur bahasa yang sama, substitusi juga membuat paragraf menjadi padu karena dengan keberadaannya dapat menimbulkan hubungan yang erat antarkalimat. Hal ini seperti yang diungkapkan oleh Aziz dan Juanda (2017) bahwa semakin banyak substitusi yang terjadi dalam rangkaian kalimat atau dalam rangkaian paragraf maka semakin menunjukkan bahwa pernyataan yang disampaikan 
dapat dipahami oleh pembaca. Sebaliknya, semakin tidak diperhatikan mengenai penggunaan substitusi maka suatu pernyataan yang disampaikan dapat menyebabkan pembaca kurang tanggap memahaminya.

\section{Kohesi Gramatikal Elipsis}

Piranti kohesi gramatikal elipsis yang ditemukan dalam penelitian ini berjumlah 24 buah. Elipsis nominal ditemukan sebanyak 23 piranti, elipsis verbal tidak ditemukan, dan elipsis klausal sebanyak 1 piranti. Berikut ini adalah contoh data tersebut.

(10) Ketika Popi kembali, ia membawa kain-kain, $\varnothing$ mengusap tubuh Barman dengan air panas. (Kuntowijoyo, 1993: 87)

(11) Barman menjalankan kuda melewati petamanan bunga itu. Pelan-pelan ia memetik sebuah $\varnothing$. (Kuntowijoyo, 1993: 98)

(12) Ia menjadi lembut pada kekasihnya itu, dan perempuan itu pun lembut padanya, tanpa ø saling menyapa. (Kuntowijoyo, 1993: 100)

Pada data (10) terdapat pelesapan subjek yaitu Popi. Subjek pada klausa kedua dilesapkan, jika tidak terjadi pelesapan subjek maka klausa kedua menjadi ia mengusap tubuh Barman dengan air panas. Tampak dengan adanya pelesapan subjek maka tuturan tersebut menjadi lebih efektif dan wacanya menjadi padu. Elipsis yang hanya meliputi subjek merupakan penghilangan subjek pada bagian klausa berikutnya yang dibiarkan kosong sehingga tidak terjadi pengulangan subjek yang sama pada klausa. Dalam hal ini, kalimat terfokus pada predikat dan objek kalimat dalam menerangkan situasi atau peristiwa yang terjadi dengan mengabaikan subjek agar tidak terjadi pengulangan yang tidak perlu dalam kalimat. Elipsis memberikan kontribusi terhadap jalannya cerita sehingga menjadi lebih efektif (Jabeen, Mehmood \& Iqbal, 2013).

Kemudian, pada data (11) terjadi sebaliknya, yaitu terjadi pelesapan objek. Jika kalimat kedua tersebut tidak terjadi proses elipsis, maka kalimat tersebut menjadi Pelanpelan ia memetik sebuah bunga. Dengan adanya pelesapan ini, pembaca novel termotivasi untuk lebih kreatif menemukan unsur-unsur yang dilesapkan, serta terjadi kepraktisan dalam berkomunikasi. Data (12) menunjukkan terjadinya pelesapan subjek. Popi yang dipanggil dengan sebutan kekasihnya dan Barman disubtitusi oleh kata keduanya. Sehingga kalimat tersebut jika tanpa pelesapan akan menjadi Ia menjadi lembut pada kekasihnya itu, dan perempuan itu pun lembut padanya, tanpa keduanya saling menyapa.

Elipsis klausal adalah proses penghilangan berupa klausa. Berikut ini adalah contoh data tersebut.

(13) Sebelumnya ia sudah mengatakan pada Popi bahwa ia tak berani mandi, kecuali kalau $\varnothing$ dengan air panas. (Kuntowijoyo, 1993: 12)

Data (13) membuktikan telah terjadinya pelesapan berupa klausa. Satuan lingual yang dilesapkan berupa subjek dan predikat. Sehingga kalimat tersebut jika tidak terjadi pelesapan menjadi Sebelumnya ia sudah mengatakan pada Popi bahwa ia tak berani mandi, kecuali kalau ia mandi dengan air panas. Terjadinya proses pelesapan ini dikarenakan demi efektifitas kalimat, kepraktisan dan efisiensi bahasa serta mengaktifkan pemikiran pembaca terhadap hal-hal yang tidak diungkapkan dalam tuturan. Hal ini sejalan dengan penelitian yang dilakukan oleh Aziz dan Juanda (2017) bahwa elipsis terjadi umumnya berada pada awal kalimat dalam rangkaian paragraf. Kemudian, elipsis yang terjadi bukan mengubah makna kalimat, melainkan kalimat yang dimaksud masih dapat ditafsirkan. 
Elipsis adalah peniadaan kata atau satuan lain yang ujud asalnya dapat diramalkan dari dari konteks bahasa atau konteks luar bahasa (Kridalaksana, 2008). Kemudian, McCarthy (1991) mendefinisikan bahwa ellipsis adalah penghilangan satuan tertentu dalam konteks tata bahasa. Elipsis ini merupakan pengantian unsur kosong (zero), yaitu unsur yang sebenarnya ada tetapi sengaja dihilangkan atau disembunyikan (Mulyana, 2005). Tujuan pemakaian elipsis ini ialah untuk mendapatkan kepraktisan bahasa. Hal ini dilakukan agar penggunaan bahasa menjadi lebih singkat, padat, dan mudah dimengerti dengan dengan cepat. Elipsis digunakan untuk efektivitas dan efisiensi berbahasa. Sedangkan menurut Sumarlam (2003) fungsi elipsis dalam wacana antara lain ialah untuk 1) menghasilkan kalimat yang efektif, 2) mencapai nilai ekonomis dalam pemakaian bahasa, 3) mencapai aspek kepaduan wacana, 4) bagi pembaca/pendengar berfungsi untuk mengaktifkan pikirannya terhadap hal-hal yang tidak diungkapkan dalam satuan bahasa, dan 5) kepraktisan berbahasa terutama dalam berkomunikasi secara lisan.

\section{Implikasinya Bagi Pembelajaran Bahasa Indonesia di SMA}

Pembelajaran bahasa Indonesia dapat diartikan sebagai serangkaian aktivitas yang dilakukan siswa untuk mencapai keterampilan berbahasa tertentu. Pembelajaran bahasa Indonesia memiliki peranan yang sangat penting bukan hanya untuk membina keterampilan komunikasi melainkan juga untuk kepentingan penguasaan ilmu pengetahuan (Abidin, 2013). Dalam kurikulum 2013 bahasa Indonesia dijadikan penghela ilmu pengetahuan. Oleh karena itu, pembelajaran bahasa Indonesia diselenggarakan dalam rangka pengembangan pengetahuan berbahasa Indonesia agar siswa dapat melakukan kegiatan komunikasi dengan baik dan benar yang meliputi banyak komponen.

Tujuan siswa belajar adalah hasil yang harus dicapai dalam proses pembelajaran. Dikarenakan pembelajaran bahasa Indonesia bertujuan untuk meningkatkan keterampilan siswa dalam berkomunikasi, maka diperlukan media yang dapat mendukung hal tersebut. Dalam hal ini, salah satu media yang dapat digunakan dalam pembelajaran adalah novel. Sebuah novel merupakan salah satu medium penyampaian pesan kepada pembaca mengenai suatu keadaan, tokoh, atau peristiwa tertentu. Dengan begitu, diperlukan suatu sarana agar pesan itu dapat disampaikan kepada pembaca. Hal tersebut dapat dilakukan dengan menggunakan penanda kohesi berupa substitusi dan elipsis.

Sekaitan dengan hal tersebut hasil penelitian mengenai kajian kohesi gramatikal subtitusi dan elipsis dalam novel Khotbah di Atas Bukit karya Kuntowijoyo ini dapat diimplikasikan dalam pembelajaran bahasa Indonesia di SMA. Hal demikian karena di dalam Kurikulum 2013 terdapat komponen-komponen pembelajaran yang berkaitan dengan penggunaan subtitusi dan elipsis untuk mewujudkan kepaduan paragraf serta penggunaan novel dalam pembelajaran bahasa Indonesia. Adapun, kompetensi dasar yang tercantum dalam Kurikulum 2013 kelas XI menyangkut menganalisis kebahasaan dengan mengkonstruksi sebuah resensi dari novel yang sudah dibaca. Dengan demikian, penelitian ini dapat diimplementasikan pada pembelajaran bahasa Indonesia di SMA kelas XI. Untuk itu, guru harus mampu membuat skenario pembelajaran di kelas.

Sesuai dengan Kurikulum 2013, skenario pembelajaran yang diharapkan adalah sebagai berikut. Kegiatan awal: (1) guru dan siswa saling memberi salam; (2) guru memberikan apersepsi mengaitkan keadaan sekitar sekolah dengan materi pembelajaran; (3) guru memberikan pengantar materi dasar tentang kohesi gramatikal 
subtitusi dan elipsis; dan (4) guru memberikan motivasi belajar kepada seluruh siswa. Kemudian, kegiatan inti: (1) guru membagi kelas menjadi kelompok-kelompok kecil; (2) siswa mempelajari dan menalar materi mengenai kohesi gramatikal subtitusi dan elipsis; (3) siswa dalam masing-masing kelompok ditugaskan untuk mengidentifikasi penanda subtitusi dan elipsis yang ada pada wacana novel tersebut; (4) guru meminta siswa untuk menuliskan pada secarik kertas temuan penanda subtitusi dan ellipsis pada wacana novel tersebut; (5) guru meminta siswa untuk menukar hasil kerja antarkelompok; dan (6) masing-masing kelompok ditugasi untuk mengidentifikasi dan menilai hasil kerja kelompok lain. Kegiatan akhir: (1) guru bersama-sama siswa menyimpulkan inti dari proses pembelajaran yang telah berlangsung; (2) guru memberikan motivasi dan penghargaan atas kinerja siswa; dan (3) guru memberikan pengayaan berupa tugas membaca, kemudian saling mengucapkan salam dengan siswa.

\section{SIMPULAN}

Penanda kohesi gramatikal subtitusi dan elipsis yang ditemukan dalam novel Khotbah di Atas Bukit karya Kuntowijoyo berupa subtitusi nominal, verbal, dan klausal, sedangkan elipsis berupa elipsis nominal dan klausal. Penggunaan subtitusi oleh pengarang untuk menghilangkan kemonotonan dengan menghindari pengulangan pada unsur bahasa yang sama. Dengan substitusi juga membuat paragraf menjadi padu karena dapat menimbulkan hubungan yang erat antarkalimat, sedangkan penggunaan elipsis adalah agar penggunaan bahasa menjadi lebih singkat, padat, dan mudah dimengerti dengan dengan cepat. Hal ini juga menjadikan novel ini mudah dimengerti karena tidak banyak pengulangan kata dan pengunaan bahasanya menjadi lebih variatif.

Hasil penelitian dapat diimplikasikan dalam pembelajaran bahasa Indonesia di SMA. Hal demikian karena di dalam Kurikulum 2013 terdapat komponen-komponen pembelajaran yang berkaitan dengan penggunaan kohesi gramatikal subtitusi dan elipsis untuk mewujudkan kepaduan dan keutuhan wacana serta penggunaan novel dalam pembelajaran bahasa Indonesia. Untuk itu, guru harus mampu membuat skenario pembelajaran yang akan dilaksanakan di dalam kelas.

\section{DAFTAR PUSTAKA}

Alwi, H. (2014). Tata bahasa baku bahasa Indonesia. Jakarta: Balai Pustaka.

Aryanti, S., \& Sari, R.P. (2018). Verb ellipsis in charles dickens's novel: "bleak house." Apollo Project, 7(1), 11-16. DOI: 10.34010/APOLLOV7I1.2098

Aziz., \& Juanda. (2017). Kohesi gramatikal: Kajian keutuhan wacana tugas Mahasiswa Pendidikan Bahasa dan Sastra Indonesia, Fakultas Bahasa dan Sastra, Universitas Negeri Makasar. Bahasa dan Seni, 45(2), 170-180. DOI: dx.doi.org/10.17977/um015v45i22017p170

Cook, G. (1989). Discourse. New York: Oxford University Press.

Eriyanto. (2001). Analisis wacana. Yogyakarta: Pelangi Aksara.

Halliday, M. A. K., \& Hasan, R. (1976). Cohesion in english. London: Longman Group Ltd. 
Jabeen, I., Mehmood, A., \& Iqbal M. (2013). Ellipsis, reference \& substitution as cohesive devices "The Bear" by Anton Chekhov. Academic Research International, 4(6), 1-9. Retrieved from http://www.savap.org.pk/journals/ arint./vol.4(6)/2013(4.6-15).pdf

Jumhur, N. A. (2014). Ellipsis on Teri Terry's novel "Slated": A syntactic approach. Unpublish Publication. Retrieved from http://repositori.uin-alauddin.ac.id/6336 /1/Nurun\%20Ainun\%20Jumhur.pdf

Klimova, B. F., \& Hubackopa, S. (2014). Grammatical cohesion in abstracts. ProcediaSocial and Behavioral Sciences, 116, 664-668. https://doi.org/10.1016/j.sbspro. 2014.01.276

Kridalaksana, H. (2008). Kamus linguistik. Jakarta: Gramedia Pustaka Utama.

Kuntowijoyo. (1993). Khotbah di atas bukit. Yogyakarta: Bentang.

Lobeck, A. (1995). Ellipsis functional heads, licensing, and identification. New York: Oxford University Press.

Lubis, H. H. (1994). Analisis wacana pragmatik. Bandung: Angkasa.

Mahalli, A. M, Valipour, V., \& Mahdavi, M. (2016). Translation of ellipsis as a stylistic feature: Hemingway's a farewell to arms and its Persian translation. International Journal of English Language \& Translation Studies. 4(3), 75-80. Retrieved from www.eltsjournal.org

Masniati, A., \& Azwan. (2019). Ellipsis types in Stephanie Meyer's "the short second life of Bree Tanner" using a syntactic analysis. Eternal: English, Teaching, Learning, and Research Journal, 5(1), 66-74. Retrieved from http://journal.uinalauddin.ac.id/index.php/Eternal/article/view/6655

McCarthy, M. (1991). Discourse analysis for language teachers. New York: Cambridge University Press

Mulyana. (2005). Kajian wacana: Teori, metode, dan aplikasi prinsip-prinsip analisis wacana. Yogyakarta: Tiara Wacana.

Moleong, L. J. (2012). Metode penelitian kualitatif. Bandung: Remaja Rosdakarya.

Nunan, D. (1992). Mengembangkan pemahaman wacana: Teori dan praktek. (diterjemahkan oleh Elly W. Silaen). Jakarta: Rebia Indah Prakasa.

Rosyidah. (2015). Ellipsis as aesthetic formal marker of the short story "Das Brot". KnE Social Science. DOI: 10.18502/kss.v3i10.3895

Sudaryanto. (2015). Metode dan aneka teknik analisis bahasa. Yogyakarta: Sanata Dharma University Press. 
Sudaryat, Y. (2009). Makna dalam wacana. Jakarta: Yrama Widya.

Sumarlam, M. S. (2003). Teori dan praktik analisis wacana. Surakarta: Pustaka Cakra.

Syamsuddin, A. R. (1998). Studi wacana: Teori-analisis-pengajaran. Bandung: Mimbar Pendidikan Bahasa dan Seni FPBS IKIP Bandung.

Widiani, L. P. P. (2016). Subtitution and ellipsis as cohesive devices in novel sweet frannie by Susan Sallis. E-Jurnal Humanis, 14(1), 59-65. https://ojs.unud.ac.id/ index.php/sastra/article/view/19368/12839

Wiyanti, E. (2016). Kajian kohesi gramatikal subtitusi dan elipsis dalam novel laskar pelangi karya Andrea Hirata. Jurnal Pendidikan Bahasa dan Sastra, 16 (2), 188202. https://doi.org/10.17509/bs_jpbsp.v16i2.4481

Youlanda, E., Zahar, E., \& Sujoko. (2018). Fungsi subtitusi sebagai bentuk penghilangan kemonotonan dalam novel "Surga Yang Tak Dirindukan 2" karya Asma Nadia. Aksara: Jurnal Ilmiah Pendidikan Bahasa dan Sastra Indonesia, 2(2), 21-28. http://aksara.unbari.ac.id/index.php/aksara/article/view/69

Zaimar, O. K. S., \& Harahap, A. B. (2011). Telaah wacana teori dan penerapannya. Depok: Komodo Books. 